\title{
The role of albumin in the release of platelet-activating factor by mouse preimplantation embryos in vitro
}

\author{
A. J. Ammit and C. O’Neill* \\ Human Reproduction Unit, Departments of Physiology and Obstetric and Gynaecology, \\ University of Sydney, Royal North Shore Hospital of Sydney, St Leonards, NSW 2065 Australia
}

\begin{abstract}
Platelet-activating factor (PAF) produced by embryos remained associated with mouse four-cell embryos after culture in vitro and was also released into the medium. The release of PAF into medium required albumin as a media supplement and the amount of PAF released increased $(P<0.05)$ with increasing albumin concentration. There was a trend for the amount of PAF remaining associated with embryos to decrease as the extracellular albumin concentration increased. The association of released PAF with albumin was confirmed by size fractionation with size exclusion membranes and high performance gel filtration, and by affinity chromatography (Cibacron blue and anti-BSA) and native PAGE. PAF released from embryos was not degraded by serum PAF:acetylhydrolase (PAF:AH; E.C. 3.1.1.47) after exposure for $24 \mathrm{~h}$ to the serum in vitro, while an equivalent concentration of synthetic PAF added to identical media was readily degraded, suggesting that PAF released from the embryo was protected from PAF:AH action. However, when the medium was subjected to organic extraction by the Bligh-Dyer (methanol/chloroform) method and the resulting extract added to equivalent media, embryo-derived PAF was readily degraded by PAF:AH. Furthermore, PAF in embryo-conditioned medium (30 two-cell embryos for $24 \mathrm{~h}$ ) could not be detected after direct assay of the culture medium by radioimmunoassay or bioassay (platelet aggregation in vitro), yet after extraction, purification and addition to medium with BSA, the embryo-derived PAF was readily detected in either assay. To determine whether the different behaviour of synthetic PAF and embryo-derived PAF resulted from differences in the nature of their binding to albumin, the location to which PAF bound was assessed by limited proteolytic digestion of albumin. Digestion with pepsin or trypsin showed that embryo-derived PAF was located exclusively between amino acids 240 and 386 (domain II) of albumin. Most synthetic PAF added to equivalent medium not exposed to embryos was not at this location, suggesting that PAF released from embryos bound to a site on albumin not generally accessible to synthetic PAF added to similar media.
\end{abstract}

\section{Introduction}

Platelet-activating factor (PAF; I-O-alkyl-2-acetyl-sn-glycero-3phosphocholine) is a biologically active ether phospholipid. It has wide tissue distribution and may be a potent mediator involved in inflammation, neural activity and reproduction. The preimplantation embryos from a variety of mammalian species release PAF in vitro (mouse: O'Neill, 1985a; Kodama et al. 1989; human: Collier et al, 1990; Punjabi et al., 1990; sheep: Battye et al., 1991; rabbit: Minhas et al., 1993). Embryo-derived PAF may act as an autocrine stimulant of embryonic metabolism and growth (Ryan et al., 1990; Roberts et al., 1993; Nishi et al., 1995; Stoddart et al., 1996; O'Neill, 1997) and also causes alterations to some aspects of maternal physiology in early pregnancy, including thrombocytopenia and splenic contraction (O'Neill, 1985b), changes in the vasculature of the uterine tube of mice (Stein and O'Neill, 1994), regulation of embryo

*Correspondence.

Received 16 September 1996. transport through the oviduct in the hamster (Velasquez et al., 1995), and the induction of early pregnancy factor expression (Orozco et al., 1986). PAF may also modulate prostaglandin secretion by the uterus in vitro (Smith and Kelly, 1988) and in vivo (Battye et al., 1992) and the activation of phospholipase C (Ahmed and Smith, 1992; Battye et al., 1992) and phospholipase D (Ahmed et al., 1992) in the uterus.

Platelet-activating factor is generally considered to have a very short half-life in vivo (Stafforini et al., 1989). If this is also the case in the reproductive tract, it is uncertain that embryoderived PAF would accumulate to sufficient concentrations to be able to exert the effects claimed for it. It has been shown that the activity of PAF:acetylhydrolase (PAF:AH; E.C. 3.1.1.47) in the mouse uterus is regulated by the ovarian steroids (O'Neill, 1995). Progesterone suppresses PAF:AH activity in the uterus while oestradiol increases its activity. The activity of PAF:AH in endometrial tissue and in uterine luminal fluid reached its minimum on days $2-3$ of pregnancy. PAF:AH activity on day 5 and day 7 of the luteal phase, for tissue and 
uterine fluid, respectively, was $780 \%$ and $5874 \%$ higher than this nadir. Thus, at the time that embryos and endometria (Angle et al., 1988) are producing PAF, PAF:AH activity in the uterus is at its lowest, suggesting that any PAF produced may have an increased half-life and thus achieve higher concentrations in the reproductive tract.

A consistent observation in this field has been that the release of PAF by embryos in vitro is highly variable. In view of the several functions that PAF may play in early pregnancy, a greater understanding of its release is warranted. Furthermore, studies of several cell types suggest that PAF retained by cells may be biologically relevant. This study investigates the extent to which embryos retain PAF and the nature of the release of PAF from embryos and its binding to carrier molecules in vitro.

\section{Materials and Methods}

\section{Mouse embryo culture}

Two-cell mouse embryos were collected from superovulated Swiss outbred albino mice ( 6 weeks old: Department of Veterinary Physiology, University of Sydney) as described by Ammit and O'Neill (1991). The embryos were collected approximately $38 \mathrm{~h}$ after the ovulatory injection of hCG and washed extensively in medium free of protein and all other macromolecules to remove exogenous proteins. Thirty two-cell embryos were cultured for $24 \mathrm{~h}$ at $37^{\circ} \mathrm{C}$ in $5 \% \mathrm{CO}_{2}$ in air in tissue culture tubes (Falcon 2003: Becton-Dickinson, Franklin Lakes, NJ) with $1 \mathrm{ml}$ of embryo culture medium containing 0,3 , 30 or $3000 \mathrm{mg} \mathrm{BSA} \mathrm{ml}^{-1}$ (Pentex: Miles, Kankakee, IL). Embryos were cultured in human tubal fluid medium (HTFM; Quinn et al., 1985). For all experiments, control tubes were prepared in an identical manner but did not have embryos added and were incubated for an equivalent period. After culture for $24 \mathrm{~h}$, the media and embryos or media alone (control) were removed from each tube and placed into an organ culture dish (Falcon). Embryos were recovered from the dish, rinsed in Hepes-buffered HTFM (Quinn $e$ t al., 1985) with $3 \mathrm{mg} \mathrm{BSA} \mathrm{ml}{ }^{-1}$, collected in minimal volume $(2-3 \mathrm{ml})$ and stored frozen. The remaining embryo-conditioned medium (ECM) or control medium was gassed with $100 \% \mathrm{CO}_{2}$ and stored at $-20^{\circ} \mathrm{C}$. Before PAF extraction and bioassay, embryos were resuspended in HTFM $+3 \mathrm{mg} \mathrm{BSA} \mathrm{ml}^{-1}$ and sonicated for $10 \mathrm{~s}$.

\section{Platelet-activating factor extraction and assay}

Platelet-activating factor was extracted by a modification (Collier et al., 1990) of the Bligh-Dyer organic extraction method (Bligh and Dyer, 1959), followed by partial purification by thin-layer chromatography (Collier et al., 1990). PAF was measured in a platelet aggregation bioassay or radioimmunoassay (NEN Du Pont, Wilmington, IL, USA) as described by Ammit and O'Neill (1991).

\section{Preparation of embryo-conditioned media pools}

For production of large amounts of material for purification and characterization studies, pools of ECM of defined embryo-derived PAF bioactivity were produced by assaying aliquots from individual ECM samples. Those with detectable PAF concentrations were pooled. An ECM pool with an embryo-derived PAF concentration of $10 \mathrm{ng} \mathrm{ml}^{-1}$ in medium containing $3 \mathrm{mg} \mathrm{BSA} \mathrm{ml}^{-1}$ resulted. An ECM pool with $30 \mathrm{mg} \mathrm{BSA} \mathrm{ml}^{-1}$ was also prepared and this had an embryoderived PAF concentration of $15 \mathrm{ng} \mathrm{ml}^{-1}$ (this was used for high performance gel filtration chromatography and limited proteolysis experiments).

Control tubes containing HTFM $+3 \mathrm{mg} \mathrm{BSA} \mathrm{ml}^{-1}$ or $\mathrm{HTFM}+30 \mathrm{mg} \mathrm{BSA} \mathrm{ml}^{-1}$ were treated in the same manner, but not exposed to embryos. The control media were pooled and halved. One half was left untreated and acted as a control blank for all procedures described and the other half was used to prepare control solutions containing synthetic PAF ( $\mathrm{L}-\alpha-$ phosphatidylcholine, $\beta$-acetyl- $\gamma$-O-alkyl; Sigma Chemical Co., St Louis, $\mathrm{MO}$ ) to an equivalent concentration to embryoderived PAF in the ECM pools. This control medium is referred to as the 'synthetic PAF' pool. It was made by dissolving PAF in chloroform (BDH, Poole) to a concentration of $1 \mathrm{mg} \mathrm{ml}^{-1}$. Aliquots of this stock solution were added to a siliconized glass test tube (Becton-Dickinson) and then reduced to dryness under a continuous stream of dry nitrogen. Control medium was then added to the tube containing PAF. The PAF was dissolved by vortexing the medium for $3 \mathrm{~min}$, and then incubating for at least $1 \mathrm{~h}$ at $37^{\circ} \mathrm{C}$ under $5 \% \mathrm{CO}_{2}$ in air (although incubation for up to $24 \mathrm{~h}$ achieved an identical result). More than $95 \%$ of the PAF was dissolved with this technique. A trace amount of [ $\left.{ }^{3} \mathrm{H}\right] \mathrm{PAF}$ (1-O-[hexadecyl-1',2',-

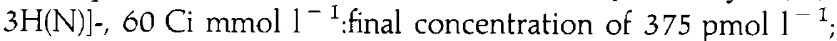
NEN Du Pont) was added to both embryo-conditioned and control media. This trace was detected by liquid scintillation counting (Eco-lite: ICN Biomedicals, Costa Mesa, CA) in aliquots after each processing step.

\section{Assessment of susceptibility of embryo-derived platelet-activating factor to hydrolysis by platelet-activating factor:acetylhydrolase}

The effect of PAF:AH on embryo-derived PAF in the ECM pool was compared with its effect on PAF in the corresponding synthetic PAF pool. Serum was collected from a healthy volunteer. It was heat-inactivated $\left(20 \mathrm{~min}\right.$ at $\left.56^{\circ} \mathrm{C}\right)$, half was left untreated and the remainder acid-treated with $1 \mathrm{~mol} \mathrm{HCl} \mathrm{l}{ }^{-1}$ $(\mathrm{BDH})$ to $\mathrm{pH} 3$ for $20 \mathrm{~min}$ at $37^{\circ} \mathrm{C}$ and then returned to $\mathrm{pH} 7.4$ by $1 \mathrm{~mol} \mathrm{NaOH}{ }^{-1}(\mathrm{BDH})$. This treatment deactivates PAF:AH (Wardlow et al., 1986). The PAF:AH specific activity was measured as described by O'Neill (1995). Untreated or acid-treated sera $(100 \mu \mathrm{l})$ were added to $5 \mathrm{ml}$ tissue culture tubes containing $900 \mu \mathrm{l}$ of ECM pool or corresponding synthetic PAF pool, and after $24 \mathrm{~h}$ incubation at $37^{\circ} \mathrm{C}$, in $5 \% \mathrm{CO}_{2}$ in air, medium was extracted and the PAF concentration measured by bioassay.

\section{Detection of platelet-activating factor without prior organic extraction}

Preliminary experiments showed that embryo-derived PAF was not detectable when either bioassays or radioimmunoassay were performed on ECM without prior organic extraction. 
Experiments were performed to characterize whether this was a feature of PAF released from embryos or whether it also occurred with synthetic PAF. Three comparisons were made. (1) Synthetic PAF was prepared by two methods to assess whether the method of preparation caused artefacts in PAF detection in direct radioimmunoassay. (2) To determine whether the exposure of PAF to albumin for increasing periods influenced its detection in direct radioimmunoassay, synthetic PAF was prepared by two different methods and then added to $\mathrm{HTFM}+3 \mathrm{mg} \mathrm{BSA} \mathrm{ml}^{-1}$ and left at $37^{\circ} \mathrm{C}$ in $5 \% \mathrm{CO}_{2}$ in air, for $1 \mathrm{~h}$ or $24 \mathrm{~h}$. The latter condition exactly controlled for the conditions of embryo culture. (3) Embryo-conditioned medium or synthetic PAF was assayed in the radioimmunoassay and bioassay without organic extraction, and then compared with the results for PAF present following Bligh-Dyer extraction, partial purification of PAF by TLC and addition to $\mathrm{HTFM}+3 \mathrm{mg} \mathrm{BSA} \mathrm{ml}^{-1}$.

The two methods of preparation of PAF were: (a) that described above which involved dissolving PAF in chloroform, bringing it to dryness under nitrogen in a siliconized tube and then dissolving it by the addition of HTFM $+3 \mathrm{mg} \mathrm{BSA} \mathrm{ml}^{-1}$; and (b) first dissolving dry PAF in $20 \mu \mathrm{l}$ of $100 \%$ ethanol (BDH) and then adding $1 \mu \mathrm{l}$ PAF in ethanol to $1 \mathrm{ml}$ of HTFM $+3 \mathrm{mg}$ BSA $\mathrm{ml}^{-1}$. The medium was vortexed for $3 \mathrm{~min}$, and then incubated for $1 \mathrm{~h}$ and $24 \mathrm{~h}$ at $37^{\circ} \mathrm{C}$ under $5 \% \mathrm{CO}_{2}$ in air. The efficiency of these two methods in bringing PAF to solution was monitored by using trace $\left[{ }^{3} \mathrm{H}\right] \mathrm{PAF}$ as described above.

Each of these experiments was performed in triplicate. For the experiments in (1) and (2), the PAF solutions were subjected to several serial dilutions before assay, which allowed standard curves to be generated and confirmation of linearity.

\section{Characterization of the protein carrier of PAF in ECM}

Aliquots $(1 \mathrm{ml})$ of the synthetic PAF and ECM pools were added to a $30 \mathrm{kDa}$ molecular mass cut-off microconcentrator (Centricon-30: Amicon, MA) and separated into $>30 \mathrm{kDa}$ (concentrate) and $<30 \mathrm{kDa}$ (filtrate) fractions by centrifugation using a fixed angle $\left(28^{\circ}\right)$ rotor $(3000 \mathrm{~g}$ for $\mathrm{Ih}$ at room temperature). The volume of the concentrate was approximately $50 \mu \mathrm{l}$. Both the concentrate and filtrate were brought to $1 \mathrm{ml}$ with the addition of $\mathrm{HTFM}+3 \mathrm{mg} \mathrm{BSA} \mathrm{ml}^{-1}$, PAF extracted and measured by bioassay. Protein concentration (Protein Microassay: Bio-Rad, Richmond, MA) and recovery of the $\left[{ }^{3} \mathrm{H}\right] \mathrm{PAF}$ trace were also measured.

An ECM pool and its appropriate synthetic PAF pool were concentrated 6.7-fold using microconcentrators (Centricon-30) and injected into a Biosep SEC-S2000 column $(300 \mathrm{~mm}$ long $\times 7.8 \mathrm{~mm}$ internal diameter) (Phenomenex, Torrance, $\mathrm{CA}$ ) used with a Biosep-SEC-S guard column $(75 \mathrm{~mm}$ long $\times 7.8 \mathrm{~mm}$ internal diameter) (Phenomenex). The mobile phase was $0.05 \mathrm{~mol}$ phosphate buffer $1^{-1}$ (Sigma) with $20 \%$ $(\mathrm{v} / \mathrm{v})$ acetonitrile $(\mathrm{BDH}), \mathrm{pH} 7.0$, with a flow rate of $0.5 \mathrm{ml}$ $\min ^{-1}$. Fractions between the void volume and total volume of the chromatogram were assessed for recovery of radiolabelled PAF and protein concentration (using the acetonitrilecompatible Micro BCA method: Pierce, Rochford, IL), and PAF bioactivity was measured by bioassay after extraction of the fractions.
Since embryo culture was performed in an entirely defined medium with BSA as the only protein supplement, affinity chromatography (with Cibacron blue and anti-BSA) was performed to determine whether PAF was associated with albumin. Synthetic PAF and ECM pools were concentrated tenfold and $100 \mu \mathrm{l}$ of the concentrate applied to $2 \mathrm{ml}$ bed volume of Affi-gel blue (50-100 mesh: Bio-Rad) and the gel washed with $12 \mathrm{ml} 0.03 \mathrm{~mol}$ phosphate buffer $1^{-1}$, pH 7.0 (unbound fraction). BSA was eluted with $12 \mathrm{ml} 1.4 \mathrm{~mol} \mathrm{NaCl} \mathrm{l}^{-1}$ in phosphate buffer (bound fraction). The protein concentration, $\left[{ }^{3} \mathrm{H}\right] \mathrm{PAF}$ trace recovery and the bioactive PAF concentration were measured in the bound and unbound fractions.

An anti-BSA gel was prepared by coupling rabbit antibovine albumin (purified immunoglobulin fraction of rabbit antiserum: Dako, Carpinteria, CA) to cyanogen bromideactivated Sepharose (Pharmacia, Uppsala). Approximately $19 \mathrm{mg}$ of anti-BSA antibody was coupled to $5 \mathrm{ml}$ bed volume Sepharose. The capacity of this gel for BSA, applied in HTFM, was $\sim 1.5 \mathrm{mg} \mathrm{BSA}$ per $5 \mathrm{ml}$ of gel. Batch chromatography was performed in siliconized glass tubes. Concentrated samples of ECM and synthetic PAF pools were added to the matrix and mixed for $60 \mathrm{~min}$, the gel was washed with $25 \mathrm{ml} \mathrm{PBS} \mathrm{(pH} \mathrm{7.4)}$ (unbound fraction) and elution of BSA was achieved by mixing the gel for $60 \mathrm{~min}$ with $5 \mathrm{ml}$ of $0.1 \mathrm{~mol}$ glycine- $\mathrm{HCl} \mathrm{l}{ }^{-1}$ (pH 2.5) containing $0.05 \%$ Tween-80 (v/v) (bound fraction). Fractions were separated by removing supernatants after centrifugation ( $200 \mathrm{~g}$ for $2 \mathrm{~min}$ at room temperature). The $\left[{ }^{3} \mathrm{H}\right] \mathrm{PAF}$ trace recovery, protein and bioactive PAF concentration were measured in each pool.

Characterization of the binding site of platelet-activating factor on albumin by limited proteolytic analysis

Large fragments of BSA were prepared by limited proteolysis with pepsin (E.C. 3.4.23.1, from pig stomach mucosa: Sigma) and trypsin (E.C. 3.4.21.4, Type XIII, L-1-tosylamide-2phenylethylchloromethyl ketone-treated, from bovine pancreas: Sigma). The methods were as described by Feldhoff and Peters (1975) and Peters and Feldhoff (1975). Pepsin was prepared in $0.12 \mathrm{~mol}$ ammonium formate $1^{-1}$ (Sigma), pH 3.7, and trypsin in $0.04 \mathrm{~mol} \mathrm{Tris-HCl}{ }^{-1}$ (Sigma), pH 8.15. Pepsin digestion was performed at a 1:250 pepsin:BSA ratio $(w: w)$ and trypsin was used at 1:750 (w:w). The size of the major digestion products were estimated by SDS-PAGE using the PhastSystem (Pharmacia) with homogeneous 20\% gels and visualized by Coomassie blue/silver stain. Amino-terminal sequence analysis was performed to identify the peptides produced. The fragments were prepared and separated by $15 \%$ SDS-PAGE using a Mini-PROTEAN II system (Bio-Rad). Peptides were electroblotted onto polyvinylidene difluoride membranes (Bio-Rad) (Matsudaira, 1987) and visualized by Coomassie blue stain. The transferred peptides were sequenced on a Beckman LF3000 series protein sequenator (by Macquarie University Centre for Analytical Biotechnology, Sydney).

Embryo-conditioned medium and its respective synthetic PAF pool were subjected to proteolytic digestion or sham digestion and the products were separated on native PAGE gels $(15 \%)$. The gels were sliced and regions containing fragments of interest were excised. The gel slices were 
Table 1. Effect of increasing BSA concentration in culture media on the amount of platelet-activating factor (PAF) released in embryo-conditioned medium (ECM) (ng PAF $\mathrm{ml}^{-1}$ medium) or retained by two-cell murine embryos (ng PAF per embryo) after $24 \mathrm{~h}$ culture

\begin{tabular}{|c|c|c|c|c|c|c|c|c|}
\hline & \multicolumn{2}{|c|}{$0 \mu \mathrm{g} \mathrm{ml}^{-1}$} & \multicolumn{2}{|c|}{$3 \mu \mathrm{g} \mathrm{ml}^{-1}$} & \multicolumn{2}{|c|}{$30 \mu \mathrm{g} \mathrm{ml}-1$} & \multicolumn{2}{|c|}{$3000 \mu \mathrm{g} \mathrm{ml}^{-1}$} \\
\hline & $\mathrm{ECM}$ & Embryo & ECM & Embryo & ECM & Embryo & ECM & Embryo \\
\hline Median & 0.20 & 0.31 & 0.60 & 0.16 & 2.60 & 0.03 & 4.50 & 0.11 \\
\hline Q1 & 0.00 & 0.00 & 0.30 & 0.04 & 0.00 & 0.00 & 1.50 & 0.00 \\
\hline Q2 & 1.40 & 0.52 & 8.05 & 0.40 & 12.00 & 0.10 & 7.70 & 0.21 \\
\hline Mean & 0.85 & 0.36 & 4.38 & 0.25 & 9.55 & 0.20 & 5.77 & 0.13 \\
\hline SEM & 0.29 & 0.11 & 2.03 & 0.08 & 4.03 & 0.15 & 1.81 & 0.04 \\
\hline$n$ & \multicolumn{2}{|c|}{17} & \multicolumn{2}{|c|}{12} & \multicolumn{2}{|c|}{17} & \multicolumn{2}{|c|}{13} \\
\hline
\end{tabular}

homogenized in $2 \mathrm{ml}$ of $0.05 \mathrm{~mol}$ phosphate buffer $\mathrm{l}^{-1}, \mathrm{pH} 6.8$, and the proteins were allowed to diffuse out. The protein content of the gel slices was measured and used to estimate the efficiency of the enzyme reaction and protein recovery. Each fragment was subjected to organic extraction and assayed for PAF by bioassay.

\section{Statistical analysis}

Normally distributed data were analysed by comparison of means of two populations using the Student's $t$ test and summarized as means \pm SEM. Normality of data was assessed by the Shapiro-Wilk test and non-normal data were summarized as median with first and third quartile (that is, QI and Q3, respectively) and analysed by the Kruskal-Wallis test for multiple comparisons and Wilcoxon-Rank Sum test for individual comparisons.

\section{Results}

The release of PAF into culture media and its retention by mouse embryos was assessed in simple defined media in the presence of increasing concentrations of albumin as the only macromolecule. The amount of PAF released from two-cell mouse embryos increased $(P<0.05)$ with increasing albumin concentration in the culture medium (Table 1 ). In the absence of exogenous BSA, it was not possible to detect PAF in most cultures. The amount of PAF released by embryos was equivalent at 30 and $3000 \mathrm{mg}$ albumin $\mathrm{ml}^{-1}(P>0.05)$. There was a trend for an inverse relationship between embryoretained PAF and albumin concentration $(P=0.13)$, with a tendency for less PAF to be retained by cells at higher BSA concentrations. Thus, embryos produced PAF irrespective of the exogenous BSA concentration, but extracellular albumin facilitated its release into medium.

To determine whether PAF released by embryos was bound to albumin, an ECM pool and its equivalent synthetic PAF pool were fractionated into filtrate $(<30 \mathrm{kDa})$ and concentrate $(>30 \mathrm{kDa})$ using microconcentrators. For both the ECM pool and the synthetic PAF pool, all of the protein, $\left[{ }^{3} \mathrm{H}\right] \mathrm{PAF}$ and bioactive PAF were associated with the concentrate ( $>30 \mathrm{kDa}$ ). Since PAF has a defined molecular mass of $538 \mathrm{Da}$ (for an equimolar mixture of C16:0 and C18:0 PAF), these results suggest that embryo-derived PAF and synthetic PAF aggregated into large complexes or was associated with a carrier molecule with a molecular mass $>30 \mathrm{kDa}$.

All embryo-derived PAF in ECM applied to a Biosep SEC-S2000 column was recovered, and was found to comigrate with the BSA peak (Fig. Ia). By contrast, negligible $(\sim 1 \%)$ $\left[{ }^{3} \mathrm{H}\right] \mathrm{PAF}$ or bioactive synthetic PAF was recovered in the mobile phase and hence was not associated with the albumin fraction. Regeneration of the Biosep SEC-S2000 column removed the bound $\left[{ }^{3} \mathrm{H}\right] \mathrm{PAF}$ and synthetic $\mathrm{PAF}$ from the matrix.

Cibacron blue has a high capacity but incomplete selectively for albumin. Anti-BSA bound to Sepharose had a lower capacity but high selectivity for albumin. When ECM or the synthetic PAF pool were added to these affinity matrices, all PAF (embryo-derived, $\left[{ }^{3} \mathrm{H}\right] \mathrm{PAF}$ trace and unlabelled synthetic PAF) bound to the affinity columns (see Fig. 1b, c for ECM pool results). Washing of the columns with mobile phase designed to remove albumin resulted in a high recovery of PAF for both ECM and synthetic PAF ( $>80 \%$ for Cibacron blue, $>90 \%$ for anti-BSA).

The results of these four fractionation procedures showed that embryo-derived PAF consistently migrated with BSA and was therefore likely to be bound to albumin. Synthetic PAF migrated with albumin in some procedures but, unlike embryoderived PAF, it was adsorbed by the silica matrix of the HPLC gel filtration column. This difference in behaviour may suggest that synthetic PAF was bound to BSA with a lower affinity than was embryo-derived PAF.

The susceptibilities of embryo-derived PAF produced by mouse embryos in vitro and synthetic PAF to serum PAF:AH were compared. A pool of human serum was used as a source of PAF:AH. It had a specific activity of 362.7 piniol acetate removed $\min ^{-1} \mathrm{mg}^{-1}$ protein. After acid treatment and re-neutralization of the serum, the enzyme was degraded, having a specific activity of $0.4 \mathrm{pmol}$ acetate removed min $^{-1}$ $\mathrm{mg}^{-1}$ protein. The susceptibility of PAF to hydrolysis was assessed by adding $10 \%(\mathrm{v} / \mathrm{v})$ serum to both ECM and synthetic PAF pools. Susceptibility to PAF:AH was measured by comparing the amount of bioactive PAF remaining after $24 \mathrm{~h}$ exposure to untreated serum with that present after treatment with acid-treated serum. Embryo-derived PAF in ECM was unaffected by the presence of serum PAF:AH (Fig. 2a), while the PAF present in the synthetic PAF pool was 
(a)

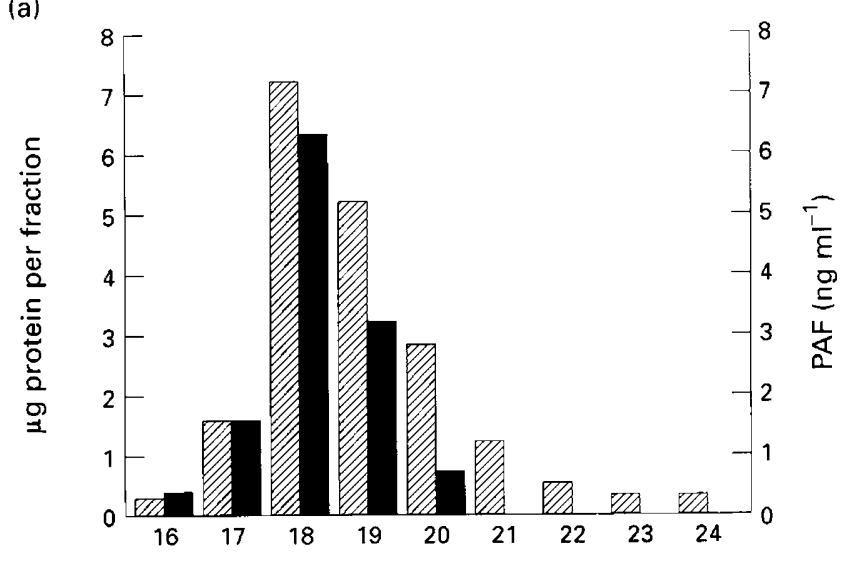

(b)

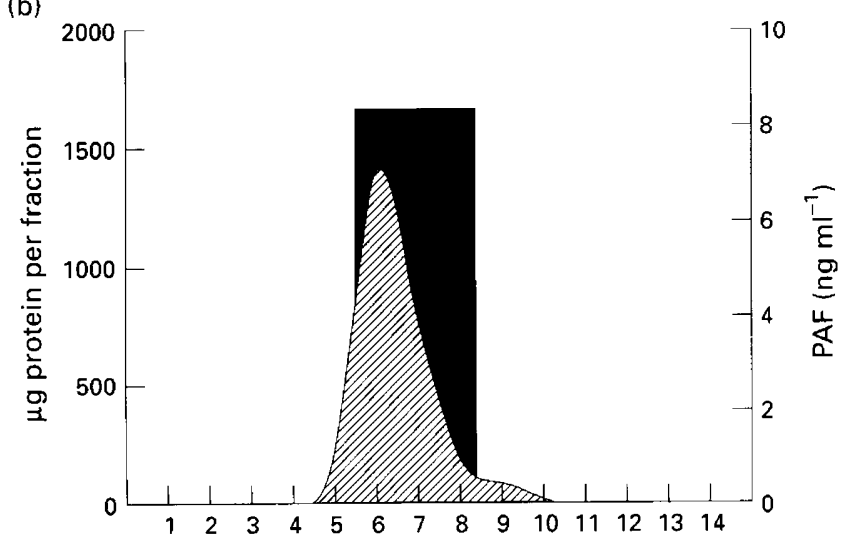

(c)

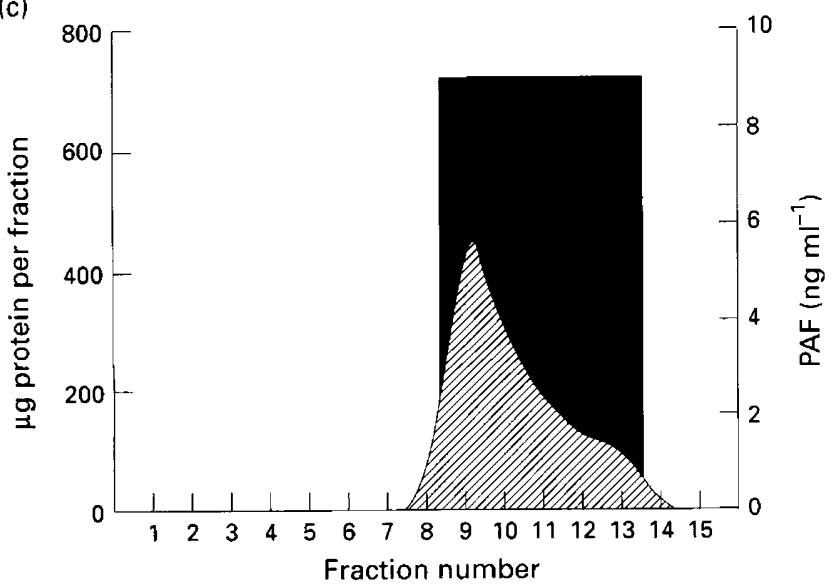

Fig. 1. (a) High performance gel filtration chromatography of the embryo-conditioned media (ECM) pool, using a Biosep-SEC S2000 column with $0.05 \mathrm{~mol}$ phosphate buffer $\mathrm{l}^{-1}$ containing $20 \%(\mathrm{v} / \mathrm{v})$ acetonitrile $(\mathrm{pH} \mathrm{7.0)}$ as the mobile phase, and a flow rate of $0.5 \mathrm{ml}$ $\min ^{-1}$. Histograms represent protein (E) and platelet-activating factor (PAF) ( ) recovery in each fraction. (b) Cibacron blue affinity chromatography of the ECM pool using Affi-gel blue. (Z) shows protein concentration for individual fractions after elution with $1.4 \mathrm{~mol} \mathrm{NaCl}$ $I^{-1}$ in $0.03 \mathrm{~mol}$ phosphate buffer $1^{-1}(\mathrm{pH} 7.0)$, while ( $)$ represents PAF concentration for the pooled bound fractions (6-8). (c) Affinity chromatography of the ECM pool using anti-BSA gel. (ש) shows protein concentration for individual fractions after elution with $0.1 \mathrm{~mol}$ glycine- $\mathrm{HCl} \mathrm{I}^{-1}(\mathrm{pH} 2.5)$ with $0.05 \%(\mathrm{v} / \mathrm{v})$ Tween 80 , while represents PAF concentration for the pooled bound fractions (9-13).
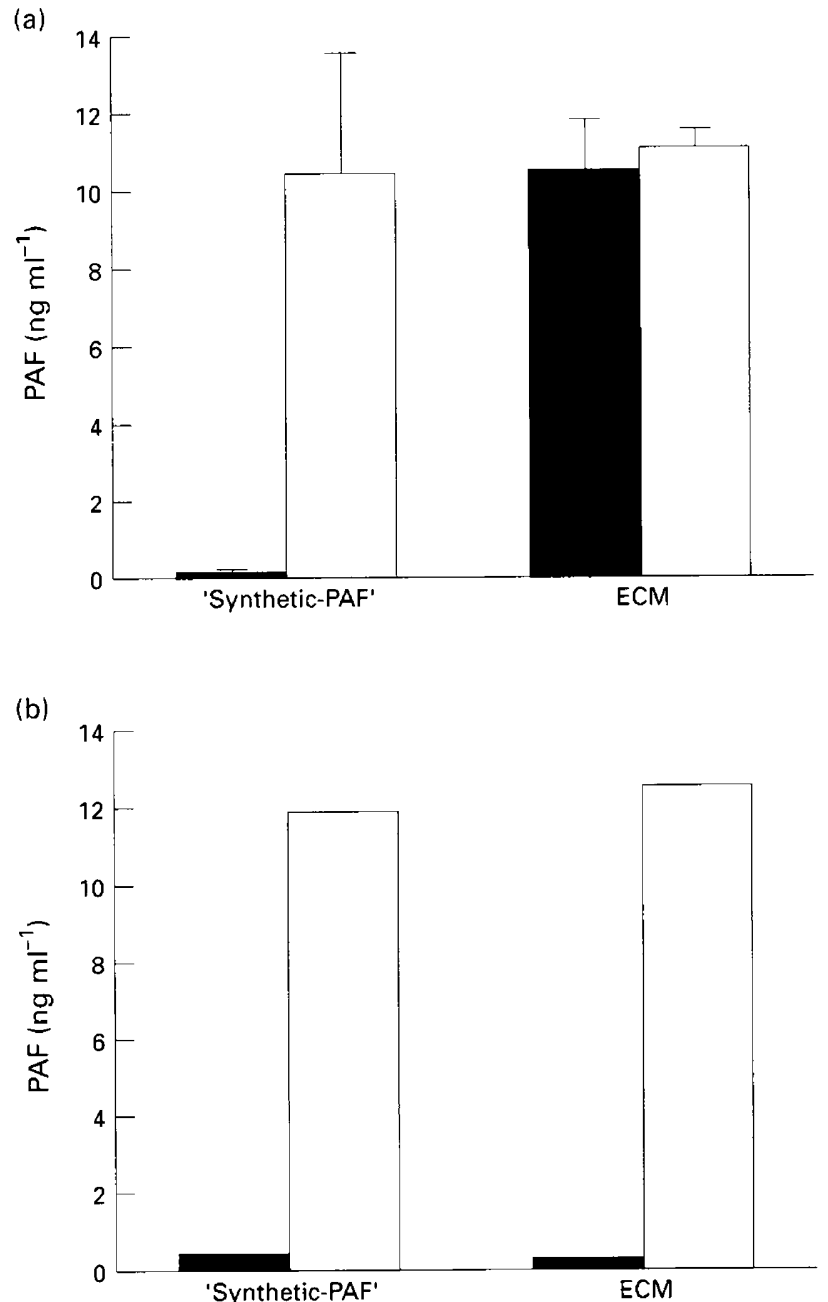

Fig. 2. Effect of $24 \mathrm{~h}$ incubation with $10 \%(\mathrm{v} / \mathrm{v})$ untreated serum ( and acid-treated serum $(\square)$ on platelet-activating factor (PAF) present in (a) synthetic PAF and embryo-conditioned media (ECM) pools, and (b) extracted synthetic-PAF and ECM pools. Results shown in (a) are means \pm SEM of three replicates and (b) shows representative results from pooled media.

degraded to a significant extent $(P<0.05)$. This difference may suggest the presence of an embryo-derived inhibitor of PAF:AH, yet the ready metabolism of $\left[{ }^{3} \mathrm{H}\right] \mathrm{PAF}$ added to embryo-conditioned media (>90\%) indicates otherwise. An alternative explanation is that embryo-derived PAF associates with a protective carrier. To examine this possibility, ECM and synthetic PAF pools were subjected to organic extraction and TLC and then added to media containing BSA. Exposure to $10 \%(\mathrm{v} / \mathrm{v})$ untreated or acid-treated serum for a further $24 \mathrm{~h}$ resulted in degradation by serum PAF:AH of both extracted embryo-derived and synthetic PAF (Fig. 2b), while acid-treated serum was without effect.

Further indirect evidence for a carrier molecule for embryoderived PAF was found during PAF assays. Media from five separate mouse embryo cultures were pooled and divided into aliquots for PAF assay by bioassay and radioimmunoassay, before and after extraction by the Bligh-Dyer method. In order to quantify PAF directly in the unextracted mouse culture media, the radioimmunoassay procedure was modified to allow 
Table 2. Effect of incubation of synthetic platelet-activating factor (PAF) (prepared by two different methods) with albumin for $\mathrm{I} \mathrm{h}$ and $24 \mathrm{~h}$ at $37^{\circ} \mathrm{C}$ under $5 \% \mathrm{CO}_{2}$ in air, then diluted with $\mathrm{HTFM}+3 \mathrm{mg} \mathrm{BSA} \mathrm{ml} \mathrm{m}^{-1}$ (to final concentration $10 \mathrm{ng}$ PAF $\mathrm{ml}^{-1}$ ) and detection with the radioimmunoassay

\begin{tabular}{crr}
\hline Incubation period $(\mathrm{h})$ & Method $1^{\mathrm{a}}$ & Method 2 \\
\hline I h & $14.2 \pm 1.8$ & $8.1 \pm 2.3$ \\
$24 \mathrm{~h}$ & $9.9 \pm 4.2$ & $6.6 \pm 0.9$ \\
\hline
\end{tabular}

Values are means $\pm \operatorname{seM}(n=3)$.

${ }^{2}$ Method 1: PAF was dissolved in chloroform, brought to dryness under nitrogen in a siliconized tube and then dissolved by the addition of $\mathrm{HTFM}+3 \mathrm{mg} \mathrm{BSA} \mathrm{ml}^{-1}$.

'Method 2: dry PAF was dissolved in $20 \mu \mathrm{l}$ of $100 \%$ ethanol and then $1 \mu \mathrm{l}$ of PAF in ethanol was added to $1 \mathrm{ml}$ of HTFM $+3 \mathrm{mg} \mathrm{BSA} \mathrm{ml}^{-1}$.

use of HTFM $+3 \mathrm{mg} \mathrm{BSA} \mathrm{ml}^{-1}$ as the diluent for the PAF standards. In neither the bioassay nor the radioimmunoassay was PAF detected in ECM before extraction. After extraction, however, all mouse embryo culture media tested were positive for PAF. The median PAF concentration was $20.5 \mathrm{ng} \mathrm{ml}^{-1}$ (Q1-Q3, 11.5-38.7 $\mathrm{ng} \mathrm{ml}^{-1}$ ) and $17.7 \mathrm{ng} \mathrm{ml}^{-1}$ (Q1-Q3, $7.7-24.7 \mathrm{ng} \mathrm{ml}^{-1}$ ) for the bioassay and radioimmunoassay, respectively. PAF present in the synthetic PAF pool was detected readily by both the radioimmunoassay and the bioassay without prior organic extraction. This inability to defect embryo-derived PAF in direct assay was not simply the result of the long incubation time of embryos, since synthetic PAF was detected after addition to identical media after either $1 \mathrm{~h}$ or $24 \mathrm{~h}$ incubation (Table 2). The ability to detect synthetic PAF in direct assay occurred with two different methods of PAF preparation (Table 2), suggesting that this may be a general feature of soluble PAF. The amount of PAF detected where PAF had been prepared as an ethanolic solution tended to be lower than the other method. This appears to be at least partly due to the lower solubility of PAF with this method, as assessed by the recovery of $\left[{ }^{3} \mathrm{H}\right] \mathrm{PAF}$ trace $(100.0 \%$ recovery for method 1 versus $80.4 \%$ for method 2 ). Taken together, these results suggest that the inability to detect embryoderived PAF in direct assay may be a property acquired upon release of PAF from the embryo.

The relative resistance of PAF in ECM to the actions of PAF:AH and its inability to be detected in direct assays is consistent with embryo-derived PAF being associated with a carrier. Synthetic PAF or extracted embryo-derived PAF added to media containing albumin did not show these properties. Taken at face value, these results are not consistent with albumin acting as a carrier molecule. Yet, characterization studies showed that embryo-derived PAF migrated with albu$\min$. To reconcile these different results, further characterization of the nature of the association of embryo-derived PAF with albumin was performed by undertaking limited proteolytic digestion of albumin.

Large peptic and tryptic fragments of BSA (583 amino acid residues) were prepared by limited proteolysis using established methods (Feldhoff and Peters, 1975; Peters and Feldhoff, 1975). The sizes of the fragments were assessed by SDS-PAGE. Limited pepsin digestion of BSA produced a single major

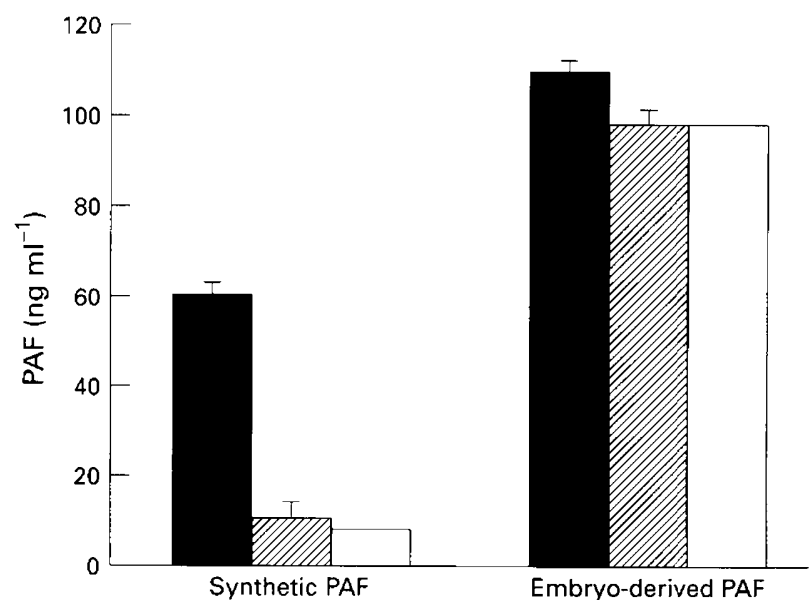

Fig. 3. Recovery of embryo-derived platelet-activating factor (PAF) (in comparison with synthetic PAF recovery) on ( $)$ sham digested BSA, () peptic fragment P-44 (residues I-386), or ( $\square$ ) tryptic fragment T-23 (residues 199-583). PAF was extracted and measured by bioassay after fragments were separated by preparative native PAGE. Histograms represent means \pm SEM of three replicates (except for $\square$, which shows representative data).

product of $45.3 \mathrm{kDa}$, referred to as P-44 (after the nomenclature of Feldhoff and Peters, 1975; Reed et al., 1975). P-44 corresponds to domains I and II of BSA, that is, amino acid residues 1-386 (Feldhoff and Peters, 1975; Reed et al., 1975). The identity of P-44 was confirmed by amino-terminal sequencing of the first ten residues. The resulting sequence $\left(\mathrm{NH}_{2}-\mathrm{Asp}-\mathrm{Thr}\right.$ His-Lys-Ser-Glu-Ile-Ala-His-Arg-) is unique to the first ten amino acids of albumin. T-23 was prepared with trypsin and had an apparent molecular mass of $36.5 \mathrm{kDa}$ on SDS-PAGE. This fragment corresponds to domains II and III of BSA (amino acids 240-583; Peters and Feldhoff, 1975; Reed et al., 1975). A number of attempts were made to determine the first ten residues of $\mathrm{T}-23$. However, reliable analysis of $\mathrm{T}-23$ could only be obtained for the first four residues $\left(\mathrm{NH}_{2}\right.$-Val-His-Lys-Ala-). This four amino acid sequence corresponds uniquely to amino acids 240-243 of albumin. A disulfide bridging of the hexapeptide amino acids 199-204 to Cys244 (which has been described by Peters and Feldhoff, 1975, following partial tryptic digestion of albumin) may have interfered with the amino-terminal sequencing of T-23 past amino acid 243 .

The association of PAF with these major proteolytic fragments was assessed by subjecting ECM or the synthetic PAF pools to digestion. As a control, similar pools were treated with vehicle not containing enzyme (sham digestion). After digestion or sham treatment, samples were applied to preparative native PAGE. The gels were sliced to recover the regions corresponding to albumin and its major digestion fragments (T-23, P-44). PAF was extracted from these slices and its concentration measured by bioassay. After sham digestion of the ECM pool, all of the embryo-derived PAF was found with undigested BSA (Fig. 3). Stoichiometric recovery of embryoderived PAF occurred on both $\mathrm{P}-44$ and $\mathrm{T}-23$ fractions of albumin from the ECM pool. By contrast, after sham digestion, only $60 \%$ of the PAF in the synthetic PAF pool was recovered on albumin and, after digestion, little synthetic PAF was recovered on P-44 and T-23 (Fig. 3). These results suggest that 
embryo-derived PAF bound to a site common to both fragments. The common region was between amino acid residues 240 and 386 . The stoichiometric relationship between the amount of embryo-derived PAF detected and the amount of P-44 and T-23 recovered indicates that this common site was also the major binding site for embryo-derived PAF. By contrast, PAF added to solution in the synthetic PAF pool was found at relatively low concentrations at this location. This suggests that PAF added to solution either does not readily bind to that site on albumin accessed by embryo-derived PAF or does so with a lower affinity and is readily dissociated by a range of manipulations.

\section{Discussion}

This work shows that a significant amount of PAF remains associated with the preimplantation mouse embryo. It has been previously shown that the mouse embryo uses simple substrates to synthesize PAF de novo (Wells and O'Neill, 1992) and possesses some key enzymes for its biosynthesis (Wells and O'Neill, 1994), suggesting that the PAF remaining associated with the embryo is likely to be produced by the embryo. The intracellular retention of PAF synthesized by cells has been reported for other cell types (see Bratton and Henson, 1989 and references therein) and it has been suggested that this may indicate a role in intracellutar (Stewart et al., 1989) or juxtacrine signalling (Zimmerman et al., 1993).

The present study also confirms previous observations (O'Neill, 1985a; Kodama et al., 1989; Ammit and O'Neill, 1991; Ammit et al, 1992) of the release of PAF into medium by mouse preimplantation embryos. It shows that this release was dependent upon the extracellular albumin concentration, with the amount of PAF released increasing as the albumin concentration increased. While small amounts of PAF were detected in some media with no albumin added, this may well be due to carry-over of some albumin from the media that was used to collect the embryos (it contained $3 \mathrm{mg} \mathrm{BSA} \mathrm{ml}^{-1}$ ). The albumin dependence of PAF release has been demonstrated for other cell types (Benveniste et al., 1972; Ludwig et al., 1985) and may well be a general phenomenon.

The trend towards a reduced embryo-retained PAF content at higher extracellular BSA concentrations suggests that the retained PAF is depleted as PAF is released from embryos in the presence of extracellular albumin. Further studies are required to confirm this trend. The regulation of PAF released by cells is not fully understood. One study (Leyravaud and Benveniste, 1989) showed that PAF released in vitro was reduced when cell numbers were high, owing to the resulting reduction in the $\mathrm{pH}$ of media. In the present study, culture conditions were standardized for embryo (hence cell) numbers, while the small number of cells present in embryo culture did not affect the $\mathrm{pH}$ of the embryo-culture media. Increasing the BSA concentration to $3 \mathrm{mg} \mathrm{ml}^{-1}$ slightly reduced $\mathrm{pH}$ ( $\sim 0.1-0.2$ units), yet this condition supported PAF release.

One study (Bratton et al., 1991) on the regulation of PAF release showed that it required transbilayer movement of PAF to the outer leaf of the plasma membrane, which was facilitated by loss of membrane phospholipid asymmetry, possibly under the regulation of cellular transglutaminase (Bratton, 1993).
Once PAF is in the outer leaf of the plasma membrane, extracellular 'acceptor' molecules are required to remove it from the membrane (Bratton et al., 1991). The present study shows that albumin is an acceptor for the release of embryoderived PAF in vitro and that its concentration in media can be one limiting factor for PAF release by embryos.

Several lines of biochemical evidence show that albumin acts directly as an embryo-derived PAF 'acceptor' rather than having an indirect role in PAF release. Albumin was the only macromolecular supplement added to media, and PAF released by the embryo added to the solution consistently migrated with BSA after high performance gel filtration chromatography, affinity chromatography on Cibacron blue and anti-BSA and after electrophoresis on native preparative PAGE. PAF has a relatively high critical micellar concentration (CMC) of 1.I $\mu \mathrm{mol} \mathrm{l^{-1 }}$ in aqueous solution (Kramp et al., 1984), which is considerably greater than the concentrations present in ECM. Similarly, the concentration of synthetic PAF used in these studies was below the CMC of PAF. In the absence of albumin, monomeric PAF added to media sticks to the surfaces of vessels (Blank et al., 1981) and is thus generally unavailable. PAF can be recovered from such surfaces by washing with media containing albumin or by washing with solvents (Ludwig et al., 1986). The low concentration of PAF in albumin-free embryo media was not due to the loss of the PAF to the vessel surfaces, since no PAF could be recovered from the vessels by methanolic washing, or with media with $3 \mathrm{mg}$ $\mathrm{BSA} \mathrm{ml} \mathrm{m}^{-1}$; rather, it appeared to be due to failure of the PAF to be released from the embryo.

In view of the observation that PAF released from embryos and synthetic PAF in solution both used albumin as an acceptor molecule, it was curious that embryo-derived PAF displayed differences in biochemical behaviour compared with synthetic PAF in culture media. There is sufficient biochemical evidence to show that the embryo-derived PAF is structurally equivalent to the synthetic PAF used in this study. That is, it is a mixture of hexadecyl and octadecyl isoforms of I-O-alkyl-2-acetyl-snglyceryl-3-phosphocholine (mass spectrophotometric analysis: Kodama et al., 1989; reverse phase HPLC: Ammit et al., 1992). Furthermore, the antibody used in the radioimmunoassay has been shown to be highly selective, with little crossreactivity with known structural analogues of PAF (Smal et al., 1990; Ammit and O'Neill, 1991). Despite this structural homology, embryo-derived PAF could not be detected by direct assays of embryo-conditioned media by either a validated bioassay or radioimmunoassay. By contrast, synthetic PAF added to such medium was measured readily by direct assay, as was embryoderived PAF after its organic extraction from media and re-addition to equivalent media. Synthetic PAF was detected readily by direct assay after incubation with media for periods of $1-24 \mathrm{~h}$. To confirm that this detection of synthetic PAF in direct assay was not simply an artefact of the method of its preparation, PAF was prepared by two different methods and both products were assayed. One method of preparation involved solubilization of dry PAF from the surface of siliconized glass tubes with medium/BSA (the standard method for preparing synthetic PAF in all other aspects of this study), while the other used PAF solubilised in ethanol and then added directly to medium/BSA. In both cases synthetic PAF was readily detected by direct (unextracted) radioimmunoassay. 
One possible explanation for the results is that the molecule released by the embryo, and bound to albumin, is not the biologically active form of PAF, but some inactive precursor which is converted to active PAF upon organic extraction. We are unaware of any precedent in the literature for such chemistry and the structure of PAF does not readily suggest a possible precursor that would be converted to PAF during methanol/chloroform extraction. Such conversion, should it occur, would need to be entirely chemical, since the nature of the organic extraction process means that it is most unlikely that enzymatic activity of any form would remain.

Platelet-activating factor:acetylhydrolase is selective for the hydrolysis of short chain acyl groups at the $\mathrm{C}_{2}$ carbon of phospholipids. Embryo-derived PAF in ECM was found not to be degraded by serum PAF:AH yet was readily degraded after extraction and preparation as an aqueous solution. Excess albumin in media can inhibit the biological actions of PAF in vitro (Tokumura et al., 1987) and reduce PAF metabolism by PAF:AH (Chao ef al., 1989; Kudolo and Harper, 1990). In the present study, it is clear that it was not simply the presence of albumin that caused embryo-derived PAF to be resistant to metabolism by PAF:AH or detection in assays, since these effects were not inhibited when the medium was subjected to organic extraction and the lipid fraction added back to the medium with an equivalent concentration and preparation of BSA. Similarly, it was not the presence of an inhibitor that masked PAF, since $\left[{ }^{3} \mathrm{H}\right] \mathrm{PAF}$ added to embryo-conditioned media was readily degraded by PAF:AH. Thus, the fractionation studies and metabolic assay results all showed consistent differences in the binding of synthetic- and embryo-derived PAF to albumin. Structural analysis of PAF binding to albumin using limited proteolytic digestion of albumin was performed to give an insight into the possible causes of these differences.

Limited proteolytic digestion of albumin from ECM showed that embryo-derived PAF was found to be associated with a region of albumin located between amino acids 240 and 386 . The relative absence of synthetic PAF from this region of albumin, together with its different biochemical behaviour, suggests that synthetic PAF either did not bind to this region of albumin or that it bound with a lower affinity, with the result that it was readily lost during biochemical manipulation.

Albumin is organized into three domains (I, II and III) that form a 'heart-shaped' molecule, similar to that of a solid equilateral triangle, with sides of $\sim 0.8 \mathrm{~nm}$ ( $\mathrm{He}$ and Carter, 1992). The region containing amino acids $240-386$ is within domain II of albumin. This domain contains a hydrophobic core which can provide a binding region for hydrophobic molecules (Brown and Shockley, 1982; Brodersen et al,, 1990). Kinetic analyses (Clay et al., 1990) indicate that albumin possesses four binding sites for PAF, although the location of these had not been defined. They had an average equilibrium dissociation constant of $10^{-7} \mathrm{~mol} \mathrm{l}^{-1}$ which was approximately tenfold greater than the embryo-derived PAF concentration in media with $3 \mathrm{mg} \mathrm{BSA} \mathrm{ml}{ }^{-1}$. Thus, it remains to be determined whether the PAF binding sites on albumin and their affinity for PAF released from cells and PAF in solution are the same. The results of this study showed that the binding to albumin of embryo-derived PAF had different characteristics from that of PAF from solution. The manner by which this difference occurs requires investigation.
The results of this study resolve some of the conflicting reports on the release of PAF by embryos. Two reports (mouse: Smal et al., 1990; rabbit: Angle et al., 1988) failed to detect PAF in ECM. In both cases embryos were cultured in protein-free medium. The results of the present study show that PAF is not released under such conditions. A third study (Ameil et al., 1989) found a PAF-like activity using the whole animal splenectomised mouse bioassay but was unable to detect PAF after ethanolic extraction and HPLC. Since synthetic PAF was recovered using this extraction procedure (albeit with poor recovery rates), Ameil et al. (1989) concluded that the PAF-like activity observed in the whole animal bioassay may not have been PAF. The results of the present study show that recovery of exogenous synthetic PAF is an unsatisfactory control for recovery of embryo-derived PAF. Ethanolic extraction is not a generally accepted methodology for recovery of cell-released PAF, although it seems satisfactory for extraction of cell-associated PAF. We suggest that conclusions regarding the release of embryo-derived PAF should only be made if fully validated Bligh-Dyer extraction procedures are followed.

Another source of conflicting evidence in the literature has been the varied reports on the ability of PAF to induce the expression of EPF activity in mice. PAF was found to induce EPF expression in mice (Orozco et al., 1986) and rabbits (Sueoka et al., 1988). However, Cavanagh et al. (1991) found, using an in vitro ovarian culture system, that ECM could induce expression of EPF, but synthetic PAF added to the same system could not. Most cells studied to date have high concentrations of PAF:AH. PAF:AH present in the culture system used by Cavanagh et al. (1991) may have resulted in a rapid degradation of synthetic PAF. The results of the present study indicate that PAF released from the embryo would have been resistant to such degradation and, thus, would have remained available for ovarian stimulation. This study shows that observed differences in the biochemical or physiological actions of ECM and synthetic PAF do not of themselves infer that the actions of ECM are not caused by PAF.

The observation of binding of embryo-derived PAF to albumin in vitro does not show that it is also the acceptor of embryo-released PAF in the reproductive tract. Albumin is a major component of the luminal fluid within the mouse reproductive tract in early pregnancy (Aitken, 1977) and is, therefore, at least a potential acceptor. However, since the present study was performed with BSA, there can be no certainty that mouse albumin would show the same type of interaction. It has been reported that BSA and rabbit serum albumin showed different potential to protect PAF from PAF:AH (Kudolo and Harper, 1990). The multiple maternal responses to early pregnancy that are apparently mediated by embryo-derived PAF show that it is released in vivo. Furthermore, there are several independent reports that untreated ECM injected into mice can induce thrombocytopenia (O'Neill, 1985b; Roberts et al., 1987; Elias et al., 1989). Thus, embryoderived PAF is both active and bioavailable in vivo and can mimic at least one of the known effects of early pregnancy (thrombocytopenia; O'Neili, 1985b).

A 'PAF-releasing factor' (molecular weight of $240 \mathrm{kDa}$ ) other than albumin has been identified in serum (Miwa et al., 1992). This protein had a high affinity $\left(10^{-9} \mathrm{~mol} \mathrm{l}^{-1}\right)$ for PAF 
and also confers protection from hydrolysis by PAF:AH. Further studies are required to identify the PAF acceptor for embryo-derived PAF in vivo.

The present study shows that some PAF remains associated with embryos, suggesting that a potential intracellular or juxtacrine mediator role for embryo-derived PAF should be investigated. An extracellular acceptor such as albumin is required for release of this mediator from embryos and emphasises the necessity of considering the association of PAF with albumin when designing methods for its assay. Studies that do not include albumin as a media component will be unlikely to detect PAF. Both radiolabelled and synthetic PAF behave differently from embryo-derived PAF. Therefore, the use of synthetic PAF preparations may not be a suitable positive control for PAF assays. The possibility that binding of embryo-derived PAF to domain II of albumin in vivo alters its biological actions requires further experimental testing. The observation that such binding elicits protection from the actions of PAF:AH in vitro infers that embryo-derived PAF may accumulate to concentrations in vivo not previously considered.

\section{Note added in proof:}

We have now demonstrated that PAF released by endothelial cells is also located on domain II of albumin in a similar protected fashion as described here. This configuration requires changes to the conformation of albumin conferred by cysteinecysteine disulfide bonds*.

*Ammit AJ and O'Neill C Studies of the nature of binding by albumin of PAF released from cells Journal of Biological Chemistry (in press)

The authors thank A. Koch for embryo culture, M. Bonafacio for chromatography advice and A. Gooley (Macquarie University Centre for Analytical Biotechnology) for amino-terminal sequence analysis. This work was supported by a grant from the National Health and Medical Research Council of Australia. A. J. Ammit was supported by an Australian Postgraduate Research Award (Australian Research Council).

\section{References}

Ahmed A and Smith SK (1992) Platelet activating factor stimulates phospholipase $C$ in human endometrium Journal of Cellular Physiology $\mathbf{1 5 2}$ 207-214

Ahmed A, Ferriani RA, Plevin R and Smith SK (1992) Platelet activating factor mediated phosphatidylcholine hydrolysis by phospholipase D in human endometrium Biology of Reproduction 47 59-65

Aitken RJ (1977) The protein content of mouse uterine flushings during pseudopregnancy Journal of Reproduction and Fertility 50 191-192

Amiel M-L, Duquenne C, Benveniste J and Testart J (1989) Platelet aggregating activity in human embryo culture media free of PAF-acether Human Reproduction 4 327-330

Ammit AJ and O'Neill C (1991) Comparison of a radioimmunoassay and bioassay for embryo-derived platelet-activating factor Human Reproduction 6 $872-878$

Ammit AJ, Wells XE and O'Neill C (1992) Structural microheterogeneity of platelet-activating factor produced by mouse preimplantation embryos Human Reproduction 7 865-870

Angle MJ, Jones MA, McManus LM, Pinckard RN and Harper MJK (1988) Platelet-activating factor in the rabbit uterus during early pregnancy Journal of Reproduction and Fertility 83 711-722

Battye KM, Ammit AJ, O'Neill C and Evans G (1991) Production of plateletactivating factor by the pre-implantation sheep embryo Journal of Reproducfion and Fertility 93 507-514
Battye KM, O'Neill C and Evans G (1992) Evidence that platelet-activating factor suppresses uterine oxytocin-induced 13,14-dihydro-15-ketoprostaglandin $\mathrm{F}_{2 u}$ release and phosphatidylinositol hydrolysis in the ewe Biology of Reproduction 47 213-219

Benveniste J, Henson PM and Cochrane CG (1972) Leukocyte-dependent histamine release from rabbit platelets. The role of $\operatorname{lgE}$, basophils and a platelet-activating factor Journal of Experimental Medicine 136 1356-1377

Blank ML, Lee T-C, Fitzgerald V and Snyder F (1981) A specific acetylhydrolase for 1-O-alkyl-2-acetyl-sn-glycero-3-phosphocholine (a hypotensive and platelef-activating lipid) Journal of Biological Chemistry 256 175-178

Bligh EG and Dyer WJ (1959) A rapid method of total lipid extraction and purification Canadian Journal of Biochemistry and Physiology 37 911-917

Bratton DL (1993) Release of platelet activation factor from activated neutrophils. Transglutaminase-dependent enhancement of transbilayer movement across the plasma membrane Journal of Biological Chemistry 268 $3364-3373$

Bratton D and Henson PM (1989) Celtular origins of PAF. In Platelet Activating Factor and Human Disease pp 23-57 Eds PJ Barnes, CP Page and PM Henson. Blackwell Scientific Publications, Oxford

Bratton DL, Kailey JM, Clay KL and Henson PM (1991) A model for the extracellular release of PAF: the influence of plasma membrane phospholipid asymmetry Biochimica et Biophysica Acta 1062 24-34

Brodersen R, Andersen S, Vorium H, Nielsen SU and Pedersen AO (1990) Multiple fatty acid binding to albumin in human blood plasma European Journal of Biochemistry 189 339-349

Brown JR and Shockley P (1982) Serum albumin: structure and characterization of its ligand binding sites. In Lipid-Protein Interactions pp 25-68 Eds PC Jost and $\mathrm{OH}$ Griffith. John Wiley, New York

Cavanagh AC, Rolfe BE, Athanasas-Platis S, Quinn KA and Morton H (1991). Relationship between early pregnancy factor, mouse embryo-conditioned medium and platelet activating factor Journal of Reproduction and Fertility 93 355-365

Chao W, Siafaka-Kapadai A, Hanahan DJ and Olson MS (1989) Metabolism of platelet-activating factor (PAF: 1-O-alkyl-acetyl-sn-glycero-3-phosphocholine) and lyso-PAF (1-O-alkyl-2-lyso-sn-glycero-3-phosphocholine) by cultured rat Knuffer cells Biochemistry Joumal 261 77-81

Clay KL, Johnson C and Henson P (1990) Binding of platelet activating factor to albumin Biochimica et Biophysica Acta 1046 309-314

Collier M, O'Neill C, Ammit AJ and Saunders DM (1990) Measurement of human embryo-derived platelet-activating factor $(\mathrm{PAF})$ using a quantitative bioassay of platelet aggregation Human Reproduction 5 323-328

Elias KA, Das AK, Pardue D, Coulam CB, Critser JK and Critser ES (1989) Alteration in platelet count during early pregnancy in the mouse American Journal of Reproductive Immunology 21 82-86

Feldhoff RC and Peters T (1975) Fragments of bovine serum albumin produced by limited proteolysis, isolation and characterization of peptic fragments Biochemistry 14 4508-4514

He XM and Carter DE (1992) Atomic structure and chemistry of human serum albumin Nature $358 \quad 209-215$

Kodama H, Muto H and Maki M (1989) Isolation and identification of embryoderived platelet-activating factor in mice Acta Obstetrica et Gynaecologica Japonica 41 899-906

Kramp W, Pieroni G, Pinckard RN and Hanahan DJ (1984) Observations on the critical micellar concentration of 1-O-alkyl-2-acetyl-sn-glycero-3phosphocholine and a series of its homologs and analogs Chemistry and Physics of Lipids $3549-62$

Kudolo GB and Harper MJ (1990) Estimation of platelet-activating factor receptors in the endometrium of the pregnant rabbit: regulation of ligand availability and catabolism by bovine serum albumin Biology Reproduction $\mathbf{4 3}$ 368-377

Leyravaud S, and Benveniste J (1989) Regulation of cellular retention of PAF-acether by extracellular $\mathrm{pH}$ and cell concentration Biochimica et Biophysica Acta 1005 192-195

Ludwig JC, Hoppens C, McManus LM, Mott GE and Pinckard RN (1985) Modulation of platelet-activating factor synthesis and release from human polymorphonuclear leukocytes (PMN): role of extracellular albumin Archives of Biochemistry and Biophysics 241 337-347

Ludwig JC, McManus LM and Pinckard RN (1986) Synthesis-release coupling of platelet-activating factors (PAF) from stimulated neutrophils. In Advances in Inflammation Research pp 111-125 Ed. I Otterness. Raven Press, New York

Matsudaira P (1987) Sequence from picomole quantities of proteins electroblotted onto polyvinylidene difluoride membranes Journal of Biological Chemistry $26210035-10038$ 
Minhas BS, Zhu Y-P, Kim H-N, Burwinkel TH, Ripps BA, and Buster JE (1993) Embryonic platelet activating factor production in the rabbit increases during the preimplantation phase Journal of Assisted Reproduction and Genetics $10366-370$

Miwa M, Sugatani J, Ikemura T, Okamoto $Y$, Ino M, Saito K, Suzuki Y and Matsumoto M (1992) Release of newly synthesised platelet-activating factor (PAF) from human polymorphonuclear leucocytes under in vivo conditions. Contribution of PAF-releasing factor in serum Journal of Immunology $\mathbf{1 4 8}$ $872-880$

Nishi O, Tominaga T, Goto Y, Hayashi K and Mori T (1995) Effects of platelet activating factor on mouse embryo implantation in vitro. Journal of Assisted Reproduction and Genetics 12 330-334

O'Neill C (1985a) Partial characterization of the embryo-derived plateletactivating factor in mice Journal of Reproduction and Fertility 75 375-380

O'Neill C (1985b) Thrombocytopenia is an initial maternal response to fertilization in mice Journal of Reproduction and Fertility 73 559-566

O'Neill C (1995) Activity of platelet-activating factor acetylhydrolase in the mouse uterus during the estrous cycle, throughout the preimplantation phase of pregnancy, and throughout the luteal phase of pseudopregnancy Biology of Reproduction $\mathbf{5 2}$ 965-971

O'Neill C (1997) Evidence for the requirement of autocrine growth factors for development of mouse preimplantation embryos in vitro. Biology of Reproduction $56 \quad 229-237$

Orozco C, Perkins T and Clarke FM (1986) Platelet-activating factor induces the expression of early pregnancy factor in female mice Journal of Reproduction and Fertility 78 549-555

Peters T and Feldhoff RC (1975) Fragments of bovine serum albumin produced by limited proteolysis, isolation and characterization of tryptic fragments Biochemistry 14 3384-3391

Punjabi U, Vereecken A, Delbeke L, Angle M, Gielis M, Gerris J, Johnston J and Buytaert P (1990) Embryo-derived platelet activating factor, a marker of embryo quality and viability following ovarian stimulation for in-vitro fertilization Journal of In Vitro Fertilization and Embryo Transfer 7 321-326

Quinn P, Kerin JF and Warnes GM (1985) Improved pregnancy rate in human in-vitro fertilization with the use of a medium based on the composition of human tubal fluid Fertility and Sterility 44 493-498

Reed RG, Feldhoff RC, Clute OL and Peters T (1975) Fragments of bovine serum albumin produced by limited proteolysis: conformation and ligand binding Biochemistry 14 4578-4583

Roberts C, O'Neill C, and Wright L (1993) Platelet activating factor (PAF) enhances mitosis in preimplantation mouse embryos Reproduction, Fertility and Development 5 271-279

Roberts TK, Adamson LM, Smart YC, Stanger JD and Murdoch RN (1987) An evaluation of peripheral blood platelet enumeration as a monitor of fertilization and early pregnancy Fertility and Sterility 47 848-854

Ryan JP, O'Neill C and Wales RG (1990) Oxidative metabolism of energy substrates by preimplantation mouse embryos in the presence of plateletactivating factor Journal of Reproduction and Fertility $89301-307$
Smal MA, Dziadek M, Cooney SJ, Attard M and Baldo BA (1990) Examination for platelet-activating factor production by preimplantation mouse embryos using a specific radioimmunoassay Journal of Reproduction and Fertility 90 $419-425$

Smith SK and Kelly RW (1988) Effect of platelet-activating factor on the release of $\mathrm{PGF}_{2 \pi}$ and $\mathrm{PGE}_{2}$ by separated cells of human endometrium Journal of Reproduction and Fertility $\mathbf{8 2} 271-276$

Stafforini DM, Carter ME, Zimmerman GA, McIntyre TM and Prescott SM (1989) Lipoproteins alter the catalytic behaviour of the platelet-activating factor acetylhydrolase in human plasma Proceedings of the National Academy of Sciences USA 86 2393-2397

Stein BA and O'Neill C (1994) Morphometric evidence of changes in the vasculature of the uterine tube of mice induced by the two-cell embryo on the second day of pregnancy journal of Anatomy 185 397-403

Stewart AG, Dubbin PN, Harris T and Dusting GJ (1989) Evidence for an intracellular action of platelet-activating factor in bovine cultured aortic endothelial cells British Journal of Pharmacology 96 503-505

Stoddart NR, Wild, AE and Fleming TP (1996) Stimulation of development in vitro by platelet-activating factor receptor ligands released by mouse preimplantation embryos Journal of Reproduction and Fertility 108 47-53

Sueoka K, Dharmarajan AM, Miyazaki T, Atlas SJ and Wallach EE (1988) Platelet activating factor-induced early pregnancy factor activity from perfused rabbit ovary and oviduct American Journal of Obstetrics and Gynecology 159 1580-1584

Tokumura A, Yoshida J-I, Maruyama T, Fukuzawa K and Tsukatani H (1987) Platelet aggregation induced by ether-linked phospholipids. 1. Inhibitory actions of bovine serum albumin and structural analogues of platelet activating factor Thrombosis Research 46 51-63

Velasquez LA, Aguilera JG and Croxatto HB (1995) Possible role of plateletactivating factor in embryonic signaling during oviductal transport in the hamster Biology of Reproduction 52 1302-1306

Wardlow ML, Cox CP, Meng KE, Greene DE and Farr RS (1986) Substrate specificity and partial characterization of the PAF-acylhydrolase in human serum that rapidly inactivates platelet-activating factor Journal of Immunology 136 3441-3446

Wells XE and O'Neill C (1992) Biosynthesis of platelet-activating factor by two-cell mouse embryos Journal of Reproduction and Fertility 96 61-71

Wells XE and O'Neill C (1994) Detection and preliminary characterization of two enzymes involved in biosynthesis of platelet-activating factor in mouse oocytes, zygotes and preimplantation embryos: dithiothrietol-insensitive cytidinediphosphocholine: 1-O-alkyl-2-acetyl-sn-glycerol-cholinephosphotransferase and acetylcoenzyme A: 1-O-alkyl-2-lyso-sn-glycero-3phosphocholine acetyltransferase Journal of Reproduction and Fertility 101 385-391

Zimmerman GA, Lorant DE, McIntyre TM and Prescott SM (1993) Juxtacrine intercellular signaling: another way to do it American Journal of Respiratory Cell and Molecular Biology 9 573-577 